\title{
Influence of a Novel Mold Inhibitor on Mechanical Properties and Water Repellency of Bamboo Fiber-based Composites ${ }^{1}$
}

\author{
Yue $\mathrm{Qi}^{2} \cdot$ Yu-Xiang Huang ${ }^{2} \cdot$ Hong-Xia $\mathrm{Ma}^{3} \cdot$ Wen-Ji $\mathrm{Yu}^{2}$ • \\ Nam-Hun $\mathrm{Kim}^{4} \cdot$ Ya-Hui Zhang $\mathbb{B}^{2, \dagger}$
}

\begin{abstract}
Effects of a novel mold inhibitor specifically for bamboo, on the properties of composite products have been confirmed in this study. The mechanical and dimensional stability properties of bamboo fiber-based composites (BFBCs) from different bamboo species were also investigated. The results showed that Burmanica Gamble possessed the highest values of modulus of elasticity (MOE) of $33.2 \mathrm{GPa}$, modulus of rupture (MOR) of $286.9 \mathrm{MPa}$, compressive strength of 182.6 MPa and shear strength of 24.0 MPa. By contrast, Phyllostochys heterocycla among all of species showed the lowest MOE of $16.3 \mathrm{GPa}$, MOR of 170.3 MPa and compressive strength of $128.9 \mathrm{MPa}$ were the lowest among all of species. Moreover, there is a remarkable variation in the swelling and water absorption between the samples with $4 \mathrm{~h}$ and $28 \mathrm{~h}$ water immersion treatment, especially Phyllostachys iridenscens. Overall, the results suggested that TCIT (Tebuconazole and 3(2H)-isothiazolone) had no significant effect on the mechanical properties compared with the control condition, and it would be utilized as an antimould of BFBCs manufacturing.
\end{abstract}

Keywords: bamboo fiber-based composites, mechanical properties, mold inhibitor, water repellency

\section{INTRODUCTION}

As a fast-growing biomaterial, bamboo is renewable, eco-friendly, and abundantly available throughout the world (Roh et al., 2004; Kang et al., 2017; Maulana et al., 2017; Park et al., 2018). The use of bamboo in many applications could help solve the wood deficit problem,and improve its utilization value (Youe et al., 2016; Lee et al., 2016; Zhang and Ma, 2016; Shin et al., 2018; Park et al., 2018). In the past twenty years, the bamboo industry has grown gradually and there are various bamboo products being produced and achieving industrialization, particularly for bamboo scrimber in China. The manufacturing technique of scrimber was developed in the mid-1970s in Australia (Yu and Yu 2013). However, it was reported that there were some key technological issues in opening bamboo fiber. As the development of technique, a new material

\footnotetext{
${ }^{1}$ Date Received January 25, 2019, Date Accepted May 13, 2019

2 Key Lab Wood Science \& Technology, State Forestry Administration, Research Institute of Wood Industry, Chinese Academy of Forestry, Xiang Shan Road, Haidian 100091, Beijing China

${ }^{3}$ Guangdong Academy of Forestry, 510520, Guangzhou China

${ }^{4}$ Department of Forest Biomaterials Engineering, College of Forest and Environmental Sciences, Kangwon National University, Chuncheon 200701, Republic of Korea

† Corresponding author: Ya-Hui Zhang (e-mail: zhangyh0206@163.com, ORCID: 0000-0002-1368-3598)
} 
called bamboo fiber-based material (BFBM) was created and utilized across many fields, and it could be applied to the blade of wind turbines, indoor and outdoor decoration, furniture, construction templates, etc.

With the development of BFBM, previous studies have investigated the effects of heat-treated method on surface and mechanical properties (Zhang et al., 2018; Zhang and Yu, 2013a, 2013b; Meng et al., 2016), steam treatment on chemical properties (Zhu et al., 2015), staining treatment on physical and mechanical properties, and appearance property of an accelerated aging test (Zhang et al., 2012). In addition, there is a challenge on biodegradation during the process of utilization, which is mainly affected by decay fungi and termites (Zabel and Morrell, 1992).

It is known that the contents of starch, sugar, and protein in bamboo are greater than those in wood, hence bamboo is easier to be eroded by fungus, especially outdoors. So far, more than fifty kinds of fungi were found to introduce blue stain, grey stain and even mildew on bamboo. Therefore, the technique of mold prevention on bamboo composites has been a concern for many researchers (Ma et al., 2013). Wei and Qin (2011) compared the anti-mold effects of Dendrocalamus affinnis composite when treated with iodopropynyl butylcarbamate (IPBC), didecyl dimethyl Ammonium Chloride (DDAC), (2-benzothiazolylthio) methyl thiocyanate (TCMTB) and IPBC + DDAC. Their results showed that IPBC was a potential fungicide according to the comprehensive consideration of its composite properties as well as its anti-mold effects. Wang et al. (2016) discussed the anti-mildew effect of bamboo timber treated by five general anti-mildew and antiseptics. However, there is no detailed information about mixed mold inhibitor TCIT (Tebuconazole and $3(2 \mathrm{H})$-isothiazolone) which was eco-friendly and highly efficient.

Thus, this study investigated the effect of mildew prevention on selected properties of a bamboo fiber-based composite including modulus of elasticity (MOE), modulus of rupture (MOR), compressive strength, shear strength, swelling of thickness and width, and water absorption. These parameters were also compared among five bamboo species, which gives more information for the application of bamboo in product manufacturing field.

\section{MATERIALS and METHODS}

\subsection{Materials}

Five bamboo species named Burmanica Gamble (B. Gamble), Neosinocalamus affinis (Rendle) Keng f. ( $N$. affinis), Dendrocalamus. yunnanicus (D. yunnanicus), Phyllostachys iridenscens (P. iridenscens), and Phyllostochys heterocycla ( $P$. heterocycla) were obtained from various places in China, and the details are shown in Table 1. The liquid phenolic formaldehyde (PF) adhesive with $44.2 \%$ solid content was applied during composite manufacture, which was supplied by

Table 1. The basic information of different bamboo species

\begin{tabular}{|c|c|c|c|c|c|c|}
\hline \multirow{2}{*}{$\frac{\text { Species }}{\text { B. Gamble }}$} & \multirow{2}{*}{$\begin{array}{c}\begin{array}{c}\text { Diameter } \\
(\mathrm{cm})\end{array} \\
7-12\end{array}$} & \multirow{2}{*}{$\begin{array}{c}\begin{array}{c}\text { Experimental } \\
\text { Position }\end{array} \\
\mathrm{B}^{*}\end{array}$} & \multicolumn{2}{|c|}{$\begin{array}{c}\text { Origin } \\
\text { (Province) } \\
\end{array}$} & \multirow{2}{*}{$\begin{array}{c}\begin{array}{c}\text { Age } \\
\text { (years) }\end{array} \\
4\end{array}$} & \multirow{2}{*}{$\begin{array}{c}\begin{array}{c}\text { Density } \\
\left(\mathrm{g} / \mathrm{cm}^{3}\right)\end{array} \\
0.727\end{array}$} \\
\hline & & & Yun & Nan & & \\
\hline N. affinis & $4-8$ & $\mathrm{~B}^{*}$ & Yun & Nan & 5 & 0.656 \\
\hline D. yunnanicus & $11-18$ & $\mathrm{M}^{*}, \quad \mathrm{~B}^{*}$ & Yun & Nan & 4 & 0.652 \\
\hline P. iridenscens & $6-7$ & B* & Yun & Nan & 5 & 0.658 \\
\hline P. heterocycla & 18 & $M^{*}, \quad B^{*}$ & An & Hui & 4 & 0.637 \\
\hline
\end{tabular}

* This parameter means different parts of bamboo: $\mathrm{M}^{*}$ is the middle part; $\mathrm{B}^{*}$ is the bottom part. 
an adhesive manufacturer (Dynea Chemical Industry Co., Ltd.) in Guangdong, China.

\subsection{Methods}

\subsubsection{Manufacture processing}

The bamboo raw materials, with the moisture contents of $8-10 \%$, were split into several strips and then produced into oriented bamboo fiber mat (OBFM) via a fluffing machine (Guosen, Qingdao, China), with the average length, width, and thickness of $2000 \mathrm{~mm} \times$ $100 \mathrm{~mm}$ to $200 \mathrm{~mm} \times 2 \mathrm{~mm}$ to $5 \mathrm{~mm}$, respectively (Fig. 1). The obtained OBFMs were steeped into a TCIT-mixed solution for $1 \mathrm{~min}$. The TCIT-OBFMs were dried and totally impregnated in PF adhesive with a $12 \%$ solid content for $10 \mathrm{~min}$. The moisture content of impregnated TCIT-OBFMS was controlled at approximately $8 \%$ to $10 \%$ through oven-drying for 12 h. Then, the prepared materials were hot-pressed at 145
${ }^{\circ} \mathrm{C}$ with a rate of $1 \mathrm{~mm} / \mathrm{min}$ (Fig. 2). The target density of products was set at $1.15 \mathrm{~g} / \mathrm{cm}^{3}$. For comparison, another set of samples were prepared without TCIT penetration.

The density of the bamboo fiber-based composite with TCIT (TCIT-BFBC) was determined by measuring its air-dry weight and volume after the composites were kept in a conditioning room with a relative humidity of $65 \pm 3 \%$ at $25{ }^{\circ} \mathrm{C} \pm 2{ }^{\circ} \mathrm{C}$ for 2 weeks. After measurement, the samples with the exact density of $1.15 \mathrm{~g} / \mathrm{cm}^{3}$ were selected for evaluating properties.

\subsubsection{Properties evaluation}

Mechanical properties were conducted on a universal testing machine (WDW-W10, Time Co., Ltd. Jinan, China). The samples with dimensions of $450 \mathrm{~mm}$ (length) $\times 24 \mathrm{~mm}$ (width) $\times 20 \mathrm{~mm}$ (thickness) were tested to determine the MOR and MOE according to GB/T 17657 (2013). Compressive strength and shear

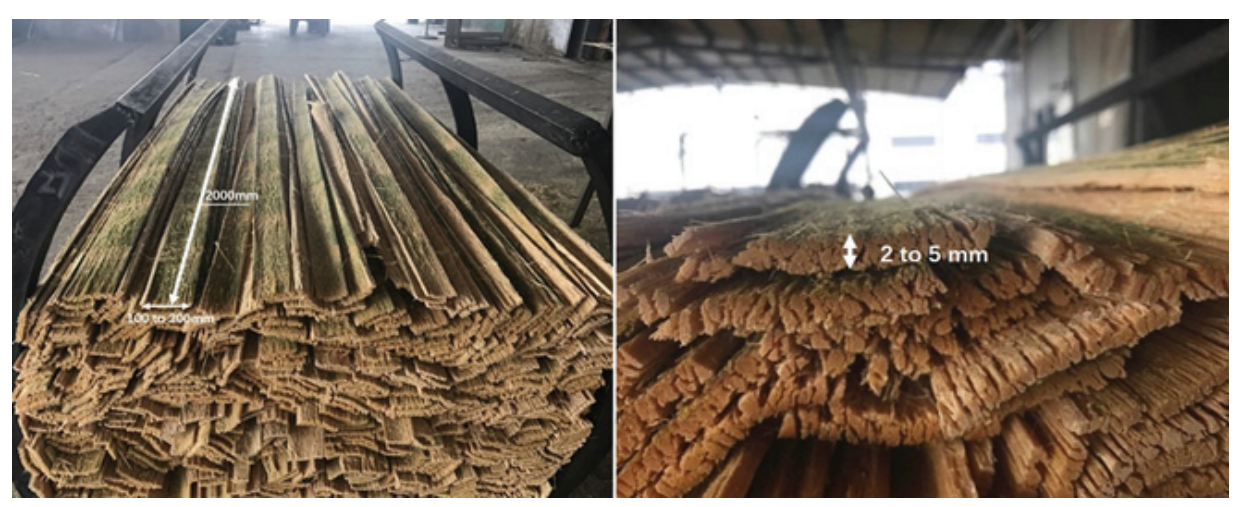

Fig. 1. Oriented bamboo fiber mats.

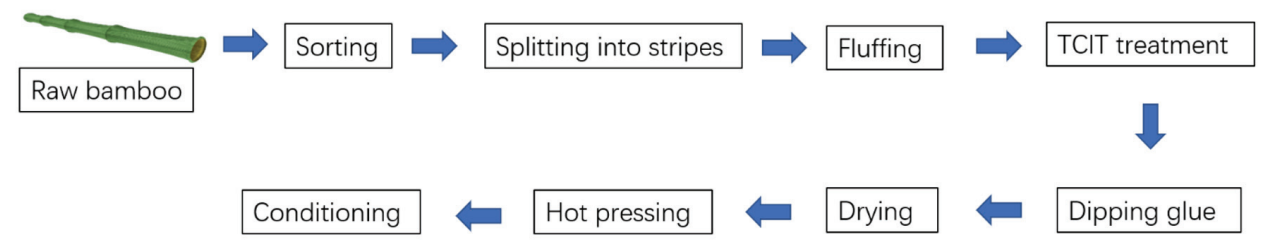

Fig. 2. Manufacturing process of TCIT-BFBC. 
strength (perpendicular to loading) were measured with the dimensions of $120 \mathrm{~mm}$ (length) $\times 40 \mathrm{~mm}$ (width) $\times 20 \mathrm{~mm}$ (thickness) and $80 \mathrm{~mm}$ (length) $\times 20 \mathrm{~mm}$ (width) $\times 20 \mathrm{~mm}$ (thickness) in accordance with ASTM D 3501 (2005) and GB/T 20241 (2006), respectively.

For the evaluation of dimensional stability, thickness swelling (TSR), width swelling (WSR) and water absorption (WAR) were evaluated according to Chinese National Standards GB/T 30364 (2013) and GB/T 20241 (2006). The whole measurements were followed by immersion in boiling water for $4 \mathrm{~h}$, oven-drying at 63 ${ }^{\circ} \mathrm{C}$ for $20 \mathrm{~h}$, and finally re-immersion in boiling water for $4 \mathrm{~h}$.

All of the measurements were repeated at least five times.

\section{RESULTS and DISCUSSION}

\subsection{Characterization of mechanical properties}

Mechanical properties of the experimental materials are displayed in Table 2. The B. Gamble specimens with TCIT treatment showed the highest values of MOR and MOE compared with other bamboo species, which were 286.9 MPa and 33.2 GPa respectively. Conversely, the lowest MOR and MOE were both found in the P. heterocycla specimens, with values of $170.3 \mathrm{MPa}$ and $16.3 \mathrm{GPa}$. The results of BFBC without TCIT treatment were somewhat different from TCIT-BFBC, and hence it was assumed that TCIT did inhibit the MOR and MOE dramatically. These results were compatible with those of Wu et al. (2014) who reported that the MOR and MOE values of $P$. heterocycla composites without preservation treatment were 150.0 MPa and $11.1 \mathrm{GPa}$ with the same density of $1.15 \mathrm{~g} / \mathrm{cm}^{3}$. MOE and MOR values of 267.1 MPa and 29.7 GPa was found in $N$. affinis bamboo scrimber in this study. Zhu and Yu (2011) also investigated the mechanical properties of bamboo scrimber, which showed 215.0 $\mathrm{MPa}$ and 26.4 GPa in the same parameters.

With regards to the compressive strength, $B$. Gamble had the highest value among all bamboo species, with recorded data of 182.6 MPa. The lowest compressive value was $128.9 \mathrm{MPa}$ that was found in P. heterocycla. In addition, $N$. affinis, $D$. yunnanicus, and $P$. iridenscens displayed the compressive value as $171.4 \mathrm{MPa}, 149.4$ $\mathrm{MPa}$ and $141.4 \mathrm{MPa}$, respectively. The reason of difference may be attributable to different cellulose content, which ascribes to the internal properties of

Table 2. Effect of TCIT treatment on mechanical properties of different bamboo species

\begin{tabular}{cccccc}
\hline Species & Method & $\begin{array}{c}\text { MOE } \\
(\mathrm{GPa})\end{array}$ & $\begin{array}{c}\text { MOR } \\
(\mathrm{MPa})\end{array}$ & $\begin{array}{c}\text { Compressive } \\
\text { Strength (MPa) }\end{array}$ & $\begin{array}{c}\text { Shear } \\
\text { Strength (MPa) }\end{array}$ \\
\hline \hline \multirow{2}{*}{ B. Gamble } & Control & $28.3(0.1)$ & $251.9(5.6)$ & $173.0(4.1)$ & $23.1(0.1)$ \\
& TCIT & $33.2(0.3)$ & $286.9(2.8)$ & $182.6(2.2)$ & $24.0(0.1)$ \\
\hline \multirow{2}{*}{ N. affinis } & Control & $29.9(0.1)$ & $256.5(2.2)$ & $168.9(0.7)$ & $16.1(0.2)$ \\
& TCIT & $29.7(0.1)$ & $267.1(8.8)$ & $171.4(3.1)$ & $18.2(0.1)$ \\
\hline \multirow{2}{*}{ D. yunnanicus } & Control & $25.7(0.5)$ & $241.6(0.3)$ & $158.0(1.5)$ & $19.8(0.8)$ \\
& TCIT & $24.9(0.1)$ & $237.6(3.0)$ & $149.4(1.7)$ & $18.6(0.4)$ \\
\hline \multirow{2}{*}{ P. iridenscens } & Control & $20.6(0.2)$ & $191.3(0.9)$ & $136.1(0.5)$ & $17.8(0.1)$ \\
& TCIT & $20.2(0.8)$ & $197.1(9.7)$ & $141.4(1.3)$ & $21.2(1.3)$ \\
\hline \multirow{2}{*}{. heterocycla } & Control & $15.5(0.1)$ & $180.7(1.0)$ & $113.9(0.2)$ & $21.9(0.9)$ \\
& TCIT & $16.3(0.2)$ & $170.3(3.3)$ & $128.9(1.1)$ & $22.2(0.6)$ \\
\hline
\end{tabular}

The number in parenthesis are the standard deviation. 
raw materials. In comparison with the results of BFBC (Table 2), there was no distinct effect of TCIT treatment on compressive strength.

The shear strength in the vertical direction represents the interfacial binding force of resin. The highest values were exhibited in the $B$. Gamble samples, while the values of $N$. affinis BFBC were the lowest among all bamboo species. The value of $B$. Gamble BFBC was 24.0 MPa, and value of $N$. affinis BFBC was 18.2 MPa, respectively. A similar trend with the results of this study was reported by He et al. (2017), and they examined that the shear strength of Phyllostachys pubescens scrimber with the density of $1.25 \mathrm{~g} / \mathrm{cm}^{3}$ were 21.85 MPa (knitted bamboo scrimber) and 18.69 MPa (common bamboo scrimber) without any mold treatment. The BFBC showed similar results with TCIT-BFBCs, except that the shear strength of $P$. iridenscens BFBC was 17.8 MPa lower than that of TCIT-BFBC (21.2 MPa). The above results are demonstrated that there is no effect of mold treatment on BFBC. Moreover, the difference of shear strength might be due to different species. Gu (2009) declared the shear strength has relationship with the chemical bond force between resin and bamboo samples, the thickness of layers, and surface treatment of bonding materials. As a consequence, all determined results of bamboo species were much higher than the required standard value of 3.5 MPa to 6.5 MPa in the Chinese standard GB/T 20241 (2006), and the shear strength would not have been affected by preservative treatment.

\subsection{Dimensional stability and water absorption}

The data on the dimensional changes are presented in Figs. 3 to 5. The swelling and water absorption of all samples increased as water immersion time increased from $4 \mathrm{~h}$ to $28 \mathrm{~h}$, which was attributed to the decrease of internal stress. Thickness swelling of the TCITBFBCs increased significantly at $28 \mathrm{~h}$ of water im-

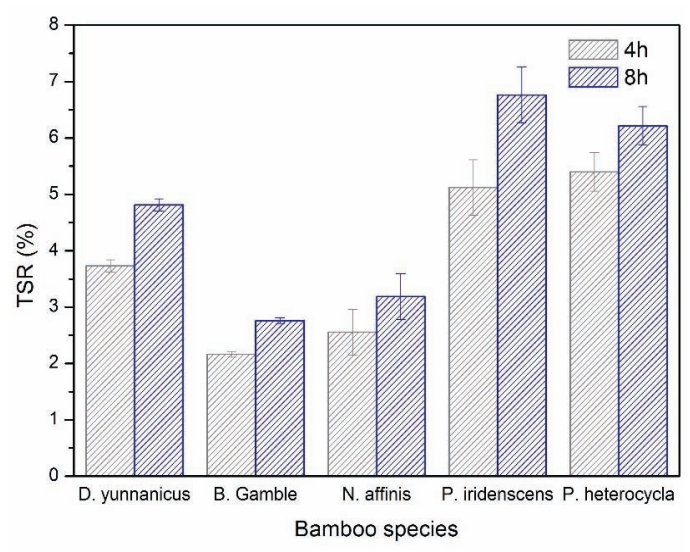

Fig. 3. Thickness swelling ratio (TSR) of different TCIT-BFBCs.

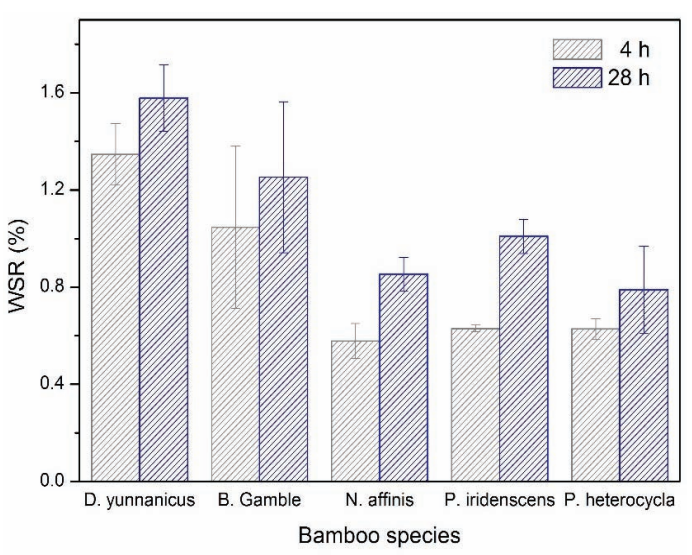

Fig. 4. Width swelling ratio (WSR) of different TCIT-BFBCs

mersion compared to $4 \mathrm{~h}$ (Fig. 3). The thickness swelling at $4 \mathrm{~h}$ of water immersion ranged from $2.16 \%$ to $5.40 \%$, and at $28 \mathrm{~h}$ ranged from $2.76 \%$ to $6.76 \%$. In addition, the data of B. Gamble was 2.5 times higher than that of the $P$. heterocycla sample. Thus, the $B$. Gamble samples presented noticeable dimensional stability compared to the other bamboo species. The width swellings of the TCIT-BFBCs increased significantly after $28 \mathrm{~h}$ of water immersion compared to $4 \mathrm{~h}$ (Fig. 4). The width swelling at $4 \mathrm{~h}$ of water immersion ranged from $0.58 \%$ to $1.35 \%$, while that of 


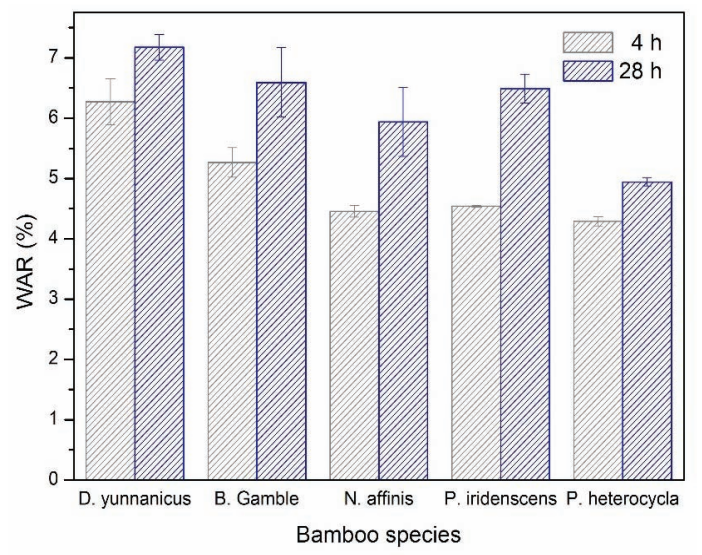

Fig. 5. Water absorption ratio (WAR) of different TCIT-BFBCs.

$28 \mathrm{~h}$ water immersion ranged from $0.79 \%$ to $1.58 \%$. The magnitude of width swelling in D. yunnanicus was the highest among all samples, while the lowest values were found separately in N. affinis and P. heterocycla at $4 \mathrm{~h}$ and $28 \mathrm{~h}$ water treatment. These results were in agreement with a previous study. Meng et al. (2016) measured that the width swelling values of $N$. affinis were $1.92 \%$ and $2.73 \%$ with $4 \mathrm{~h}$ and $28 \mathrm{~h}$ of water immersion, respectively.

As for water absorption, there was a similar trend with the variation of thickness and width swelling (Fig. 5). As the water immersion increased from $4 \mathrm{~h}$ to 28 h, the WAR of D. yunnanicus increased from $6.27 \%$ to $7.18 \%$, which was the highest value among all species. In contrast, $P$. heterocycla showed the lowest water absorption ratio with the value of $4.29 \%$ and $4.94 \%$ at the various treatment times.

Overall, there was a significant difference of swelling and water absorption in the five bamboo species. The result is due to the influence of extractives on the lignocellulosic (Umezawa, 2001). Moreover, the thickness swelling is significant higher than width swelling, which is attributed that the tendency to spring back in the width direction is lower than that along the thickness direction, and hence the stress along the thickness direction of samples was greater than that in width direction (Yu et al., 2015). The P. iridenscens samples had high variation on the above three parameters of dimensional stability at $4 \mathrm{~h}$ and $28 \mathrm{~h}$ water immersion. The mildew preservative was just as beneficial for water repellency as same as the BFBC, and had no obvious impact on dimensional stability according to the results. Thus, it is considered that the TCIT mildew preservative could be added into the BFBCs manufacturing process that could improve the durability of BFBCs but without change on dimensional stability.

\section{CONCLUSION}

The BFBC made of B. Gamble species possessed the highest values of MOE, MOR, compressive strength and shear strength, whereas the lowest MOE, MOR, and compressive strength were found for BFBC made of $P$. heterocycla, and lowest shear strength was displayed in BFBC made of D. yunnanicus. Thickness swelling, width swelling, and water absorption increased with increasing water immersion time. Overall, the results showed that the application of TCIT mold inhibitor had no impact on mechanical properties of BFBC, and it will be estimated for anti-mold effect in future work.

\section{ACKNOWLEDGMENT}

This study was financially supported by the Fundamental Research Funds of Chinese Academy of Forestry (CAF) CAFYBB2017QA015.

\section{REFERENCES}

ASTM D3501 2005 Standard test method for woodbased structural panels in compression. ASTM International, West Conshohocken, PA. 
Yue Qi $\cdot$ Yu-Xiang Huang $\cdot$ Hong-Xia Ma $\cdot$ Wen-Ji Yu $\cdot$ Nam-Hun, Kim $\cdot$ Ya-Hui Zhang

GB/T 176572013 Test methods of evaluating the properties of wood-based panels and surface decorated wood-based panels. Standardization Administration of China, Beijing, China.

GB/T 202412006 Laminated veneer lumber. Standardization Administration of China, Beijing, China.

GB/T 303642013 Bamboo scrimber flooring. Standardization Administration of China, Beijing, China.

Gu, D.Y. 2009. Study on effect factors of adhesive shear strength. Chemical Technology Market 32: 31-32.

He, S., Xu, J., Wu, Z.X., Chen, Y.H., Song, J.G. 2017. Effect of bamboo knitting on enhancing properties of bamboo scrimber. European Journal of Wood and Wood Products (online published).

Kang, C.W., Chung, W.Y., Han, J.O., Kang, H.Y. 2017. High-Temperature Drying of Bamboo Tubes Pretreated with Polyethylen Glycol Solution. Journal of the Korean Wood Science and Technology 45(2): 139-146.

Lee, J.Y., Kim, C.H., Nam, H.G., Park, H.H., Kwon, S., Park, D.H. 2016. Characteristics of Thermomechanical Pulps Made of Russian Spruce and Larix, and Myanmar Bamboo. Journal of the Korean Wood Science and Technology 44(1): 135-146.

Maulana, S., Busyra, I., Fatrawana, A., Hidayat, W., Sari, R.K., Sumardi, I., Wistara, I.N.J., Lee, S.H., Kim, N.H., Febrianto, F. 2017. Effects of Steam Treatment on Physical and Mechanical Properties of Bamboo Oriented Strand Board. Journal of the Korean Wood Science and Technology 45(6): 872-882.

Ma, X.X., Jiang, M.L., Wu, Y.Z., Wang, P. 2013. Effect of Wood Surface Treatment on Fungal Decay and Termite Resistance. BioResources 8: 2366-2375.

Meng, F.D., Yu, Y.L., Zhang, Y.M., Yu, W.J.,Gao, J.M. 2016. Surface chemical composition analysis of heat-treated bamboo. Applied Surface Science371: 383-390.
Park, S.H., Jang, J.H., Wistara, N.J., Hidayat, W., Lee, M., Febrianto, F. 2018. Anatomical and Physical Properties of Indonesian Bamboos Carbonized at Different Temperatures. Journal of the Korean Wood Science and Technology 46(6): 656-669.

Park, J.W., Kim, H., Lee, J.H., Jang, S.W., Kim, H.J. 2018. Evaluation of Mechanical Performance and Flame Retardant Characteristics of Biomass-based EVA Composites using Intumescent Flame Retardant Technology. Journal of the Korean Wood Science and Technology 46(2): 189-201.

Roh, J.K., Kim, J.K., Kim, S.I., Ra, J.B., Kim, Y.J., Park, S.J. 2004. Manufacture of wood veneerbamboo zephyr composite board-I. Properties of bamboo zephyr and composite board made from Moso, Giant Timber and Hachiku bamboo. Journal of the Korean Wood Science and Technology 32(3): 42-51.

Shin, Y.J., Yun, H.J., Lee, E.J., Chung, W.Y. 2018. A Study on the Development of Bamboo/PLA Bio-composites for 3D Printer Filament. Journal of the Korean Wood Science and Technology 46(1): 107-113.

Umezawa, T. 2001.Chemistry of extractives. In: Wood and Cellulosic Chemistry. Eds. Hon, D.N.S. Shiraishi, N. Marcell Dekker, Inc., New York, pp.213-241.

Wang, J., Yuan, S.F., Fan, H., Li, Q., Wang, H.Y. 2016. Effect of different antimildew and antiseptic agents on reconstructed bamboo timber. Journal of Zhejiang Forest Science and Technology 36: 8-12.

Wei, W.S., Qin, D.C.2011. Effects four mold inhibitor on properties of reconsolidated bamboo. Journal of Northeast Forestry University 39: 93-95.

Wu, B.L., Yu, Y.L., Qi, J.Q., Yu, W.J. 2014. Effects of bamboo bundles treated with fine fluffing and carbonized treatment on the properties of bamboo scrimber. Journal of Nanjing Forest University (Natural Sciences Edition) 38: 115-120. 
Youe, W.J., Lee, S.M., Lee, S.S., Kim, Y.S. 2016. Physical and Mechanical Properties of The Ligninbased Carbon Nanofiber-reinforced Epoxy Composite. Journal of the Korean Wood Science and Technology 44(3): 406-414.

Yu, W.J., Yu, Y.L. 2013. Development and prospect of wood and bamboo scrimber industry in China. China Wood Industry 27: 5-8.

Yu, Y.L., Zhu, R.X., Wu, B.L., Hu, Y.A., Yu, W.J. 2015. Fabrication, material properties, and application of bamboo scrimber. Wood Science and Technology 49: 83-98.

Zabel, R.A., Morrell, J.J. 1992. Wood Microbiology, Decay and its Prevention, Academic Press, New York, USA.

Zhang, Y.H., Zhu, R.X., Yu, W.J., Ren, D.H. 2012. Performance of exterior crushed bamboo-mat composite after accelerated aging test. China Wood Industry 26: 6-8.

Zhang, Y.M., Yu, W.J. 2013a. Effect of heat treatment on properties of crushed bamboo-mat composite. China Wood Industry 27: 5-8.
Zhang, Y.M., Yu, W.J. 2013b. Effect of heat treatment on properties of crushed bamboo-based fiber composite. China Wood Industry 49: 160-168.

Zhang, Y.H., Huang, Y.X., Ma, H.X., Yu, W.J., Yu, W.J., Qi, Y. 2018. Effect of different pressing processes and density on dimensional stability and mechanical properties of bamboo fiber-based composites. Journal of theKorean Wood Science and Technology 46 (4): 355-361.

Zhang, Y., Ma, Y. 2016. Study on The Preparation and Mechanical Properties of Fiberglass Reinforced Wood-Based Composite. Journal of the Korean Wood Science and Technology 44(4): 505-514.

Zhu, R.X., Yu, W.J. 2011. Effect of density on physical and mechanical properties of reconstituted smallsized bamboo fibrous sheet composite. Advanced Materials Research 150: 634-639.

Zhu, R.X., Zhang, Y.M., Yu, W.J. 2015. Changes in the chemical properties of Phyllostachys iridescens bamboo with steam treatment. BioResources 10: 5987-5993. 